\title{
Prognostic factors for progression of early- and late-stage calcific aortic valve disease in Japanese: The Japanese Aortic Stenosis Study (JASS) Retrospective Analysis
}

\author{
Kazuhiro Yamamoto ${ }^{1,2}$, Hideya Yamamoto ${ }^{3}$, Kiyoshi Yoshida ${ }^{4}$, Akira Kisanuki $^{5}$, Yutaka Hirano ${ }^{6}$, \\ Nobuyuki Ohte ${ }^{7}$, Takashi Akasaka ${ }^{8}$, Masaaki Takeuchi ${ }^{9}$, Satoshi Nakatani ${ }^{10}$, Tomohito Ohtani ${ }^{2}$, Takashi Sozu ${ }^{1}$ \\ and Tohru Masuyama ${ }^{11}$
}

Calcific aortic valve disease (CAVD) is the most common etiology of acquired valvular heart disease, and hypertension is a principal underlying disease. The Japanese Aortic Stenosis Study (JASS) Retrospective Analysis is a retrospective observational study to clarify the prognostic factors for progression of CAVD in Japanese. Data from 556 subjects who met the following criteria were analyzed: (1) $\geqslant 50$ years old; (2) calcification in any aortic valve leaflet or peak aortic jet velocity $\geqslant 2 \mathrm{~m} \mathrm{~s}^{-1}$ on an echocardiographic study performed between July 2004 and June 2007; and (3) availability of earlier echocardiographic data from within the previous 2-5 years to assess the progression of CAVD. The subjects were divided into two groups according to CAVD severity on the preceding echocardiographic examination. In early-stage subjects with calcification in one or zero leaflets who were without aortic stenosis on the preceding echocardiographic study $(n=157)$, the prognostic factors for progression were the following: (1) no use of angiotensin receptor blockers (ARB) and (2) use of warfarin. In late-stage subjects with calcification in two or three leaflets and/or aortic stenosis on the preceding echocardiographic study $(n=399)$, progression was observed in females and in subjects with low hemoglobin and a concentric left ventricle. There was no relation between medications and changes in CAVD. Prognostic factors for the progression of CAVD were different between the early and late stages. Initiation of ARB treatment during the early stage may be effective, and we should be vigilant about progression of CAVD in patients treated with warfarin.

Hypertension Research (2010) 33, 269-274; doi:10.1038/hr.2009.225; published online 8 January 2010

Keywords: angiotensin receptor blocker; aortic valve; calcification

\section{INTRODUCTION}

The prevalence of calcific aortic valve disease (CAVD) increases with aging, ${ }^{1}$ and CAVD is the most common etiology of acquired valvular heart disease in developed countries. ${ }^{2}$ Hypertension is a principal underlying disease, ${ }^{3-6}$ and previous studies in Western countries have shown an association between several clinical factors and the presence and/or progression of CAVD. 3,6,7 The Cardiovascular Health Study showed that African-American ethnicity was associated with lower risk of CAVD progression. ${ }^{6}$ Although several risk factors are shared between atherosclerotic diseases and CAVD, discrepancies in their pathogenesis have also been identified. ${ }^{8-10}$ These results highlight the necessity of investigating prognostic factors for incidence and progression of CAVD in Asian populations.

The Japanese Aortic Stenosis Study (JASS) is a multicenter, hospitalbased observational study that includes retrospective and prospective studies. The JASS Retrospective Analysis is a retrospective study to investigate the prognostic factors for progression of CAVD in Japanese subjects. As previous studies in Western countries suggest that prognostic factors differ according to CAVD severity, ${ }^{4,6,11}$ the study subjects were divided on the basis of the presence of early- $v$ s. late-stage diseases.

${ }^{1}$ The Center for Advanced Medical Engineering and Informatics, Osaka University, Suita, Japan; ${ }^{2}$ Department of Cardiovascular Medicine, Osaka University Graduate School of Medicine, Suita, Japan; ${ }^{3}$ Department of Cardiovascular Medicine, Hiroshima University, Graduate School of Biomedical Sciences, Hiroshima, Japan; ${ }^{4}$ Department of Cardiology, Kawasaki Medical School, Kurashiki, Japan; ${ }^{5}$ School of Health Sciences, Kagoshima University, Kagoshima, Japan; ${ }^{6}$ Division of Central Clinical Laboratory, Kinki University Hospital, Osakasayama, Japan; ${ }^{7}$ Department of Cardio-Renal Medicine and Hypertension, Nagoya City University Graduate School of Medical Sciences, Nagoya, Japan; ${ }^{8}$ Department of Cardiovascular Medicine, Wakayama Medical University, Wakayama, Japan; 9Second Department of Internal Medicine, University of Occupational and Environmental Health, School of Medicine, Kitakyushu, Japan; ${ }^{10}$ Department of Health Sciences, Division of Functional Diagnostics, Osaka University Graduate School of Medicine, Suita, Japan and ${ }^{11}$ Cardiovascular Division, Department of Internal Medicine, Hyogo College of Medicine, Nishinomiya, Japan

Correspondence: Dr K Yamamoto, The Center for Advanced Medical Engineering and Informatics, Osaka University, 2-2 Yamadaoka, Suita 565-0871, Japan.

E-mail: kazuhiro@medone.med.osaka-u.ac.jp

Received 7 September 2009; revised 10 October 2009; accepted 29 November 2009; published online 8 January 2010 


\section{METHODS}

\section{Subjects}

The JASS Retrospective Analysis enrolled 775 Japanese subjects who met the following criteria: (1) age $\geqslant 50$ years old; (2) markedly increased reflectivity (calcification) of any aortic valve leaflet or peak aortic jet velocity of at least $2 \mathrm{~m} \mathrm{~s}^{-1}$ on an echocardiographic recording performed between July 2004 and June 2007; and (3) availability of a report or recording from an echocardiographic study performed $2-5$ years back. Subjects with rheumatic valvular disease or who had undergone aortic valve replacement were excluded. In 556 of the 775 subjects, we were able to assess whether CAVD had progressed or not compared with the previous echocardiographic study. Mean follow-up duration was 2.8 years. In these 556 subjects, laboratory data from the time of the preceding echocardiographic examination were collected from the medical records. Phlebotomy was performed in the fasting or non-fasting state. The glomerular filtration rate (eGFR) was calculated using an equation modified for the Japanese: eGFR $\left(\mathrm{ml} \mathrm{min}\right.$ per $\left.1.73 \mathrm{~m}^{2}\right)=194 \times$ age $^{-0.287} \times$ serum creatinine $^{-1.094}$ (if female, $\times 0.739$ ). ${ }^{12}$

This retrospective study conforms to the guiding principles for epidemiologic studies of the Ministry of Health, Labour and Welfare, Japan, and was approved by all relevant institutional ethical committees.

\section{Echocardiography and assessment of the progression of CAVD}

Doppler echocardiography was conducted using commercially available echocardiographic machines as described previously. ${ }^{13,14}$.In the routine echocardiographic examination, measurements were conducted on-line. Ejection fraction was calculated using a modification of the method of Quinones et al. ${ }^{15}$ as described previously. ${ }^{13,14}$ In subjects with regional wall motion abnormalities, the biplane Simpsons' method was used. ${ }^{13,14}$ Left ventricular (LV) mass was calculated following a formula derived from data compiled by the American Society of Echocardiography ${ }^{16}$ as described previously. ${ }^{13,14} \mathrm{LV}$ mass index was calculated as a ratio of LV mass to height ${ }^{2.7}{ }^{14}$ The number of aortic valve leaflets with calcification was evaluated by an experienced cardiologist and/or sonographer.

The 556 subjects were divided into two groups according to the degree of CAVD at the preceding echocardiography. The group with early-stage CAVD comprised subjects with calcification on one or no leaflet and peak aortic transvalvular flow velocity $<2 \mathrm{~m} \mathrm{~s}^{-1}(n=157)$. $^{6,17-19}$ The late-stage CAVD group comprised subjects with two or three calcified aortic valves and/or with peak aortic transvalvular flow velocity of $\geqslant 2 \mathrm{~m} \mathrm{~s}^{-1}(n=399)$. Eleven patients had bicuspid aortic valve, and all met the criteria for late-stage CAVD. As of their small number, their data were analyzed with other late-stage subjects.

Progression in the late-stage group was defined as a $\geqslant 0.3 \mathrm{~m} \mathrm{~s}^{-1}$ per year rate of increase in peak aortic transvalvular flow velocity at follow-up, as described previously..$^{17,20}$ In the early-stage group, progression was defined as the appearance of two or three newly calcified leaflets or the onset of aortic stenosis (peak aortic transvalvular flow velocity of $\geqslant 2 \mathrm{~m} \mathrm{~s}^{-1}$ ) at follow-up.

\section{Statistical analysis}

Statistical analysis was performed using SAS 9.1 (SAS Institute, Cary, NC, USA). Continuous data are summarized as mean \pm s.d. Categorical data are presented as percentages. The Student's $t$-test was used for normally distributed data, especially demographic data, and the Wilcoxon rank sum test was used for non-normally distributed data (for example, laboratory data). The $\chi^{2}$ test was used for binary data (for example, use of concomitant medication). The Mantel test was applied for ordered categorical data, that is, the degree of aortic and mitral regurgitation. The significance level was fixed at $5 \%$.

\section{RESULTS}

Subject characteristics

Baseline characteristics are listed in Table 1. Age and prevalence of hypertension, diabetes mellitus, dyslipidemia and renal insufficiency were increased in subjects with late-stage CAVD. Systolic blood pressure was higher, but diastolic blood pressure was lower in latevs. early-stage subjects. The prescription rate of angiotensin-converting
Table 1 Subject characteristics

\begin{tabular}{|c|c|c|c|}
\hline & All & Early stage & Late stage \\
\hline$n$ & 556 & 157 & 399 \\
\hline Age (years) & $73.7 \pm 9.0$ & $71.1 \pm 8.0$ & $74.7 \pm 9.2^{*}$ \\
\hline Male (\%) & 52.3 & 55.4 & 51.1 \\
\hline Body mass index $\left(\mathrm{kg} \mathrm{m}^{-2}\right)$ & $22.5 \pm 3.4$ & $23.0 \pm 3.2$ & $22.3 \pm 3.4$ \\
\hline Systolic blood pressure $(\mathrm{mm} \mathrm{Hg})$ & $135 \pm 18$ & $133 \pm 16$ & $137 \pm 19$ * \\
\hline Diastolic blood pressure $(\mathrm{mm} \mathrm{Hg})$ & $74 \pm 11$ & $77 \pm 12$ & $73 \pm 11^{*}$ \\
\hline \multicolumn{4}{|l|}{ Comorbidity (\%) } \\
\hline Hypertension & 72.8 & 65.6 & $75.7^{*}$ \\
\hline Diabetes mellitus & 29.0 & 22.9 & $31.3^{*}$ \\
\hline Dyslipidemia & 49.1 & 40.1 & $52.6^{*}$ \\
\hline Renal insufficiency & 23.4 & 12.1 & $27.8^{*}$ \\
\hline \multicolumn{4}{|l|}{ Medications (\%) } \\
\hline Angiotensin converting enzyme inhibitor & 20.5 & 33.8 & $15.3^{*}$ \\
\hline Angiotensin receptor blocker & 30.9 & 23.6 & $33.8^{*}$ \\
\hline$\beta$-blocker & 21.8 & 28.0 & $19.3^{*}$ \\
\hline Calcium channel blocker & 41.7 & 49.0 & $38.9^{*}$ \\
\hline Warfarin & 18.9 & 17.2 & 19.6 \\
\hline Statins & 27.5 & 24.8 & 28.6 \\
\hline Oral hypoglycemic medications & 10.8 & 9.6 & 11.3 \\
\hline Insulin & 4.5 & 6.4 & 3.8 \\
\hline
\end{tabular}

${ }^{*} P<0.05$ vs. early stage.

Table 2 Preceding echocardiographic data

\begin{tabular}{|c|c|c|c|}
\hline & A/l & Early stage & Late stage \\
\hline Left atrial dimension ( $\mathrm{mm}$ ) & $41 \pm 8$ & $40 \pm 9$ & $41 \pm 8^{*}$ \\
\hline Left ventricular end-diastolic dimension (mm) & $48 \pm 7$ & $49 \pm 7$ & $48 \pm 7$ \\
\hline Left ventricular end-systolic dimension (mm) & $31 \pm 7$ & $31 \pm 8$ & $30 \pm 7$ \\
\hline Ejection fraction (\%) & $66 \pm 11$ & $65 \pm 12$ & $66 \pm 10$ \\
\hline Left ventricular mass index $\left(\mathrm{g} \mathrm{m}^{-2.7}\right)$ & $55.3 \pm 17$ & $51.2 \pm 15.7$ & $57.0 \pm 17.6$ \\
\hline
\end{tabular}

The degree of aortic regurgitation (\%)

$\begin{array}{lccc}\text { O II } & 37.8 & 52.2 & 32.1 \\ \text { II } & 34.4 & 28.7 & 36.6 \\ \text { III } & 21.6 & 16.6 & 23.6 \\ \text { IV } & 5.8 & 2.6 & 7.0 \\ & 0 & 0 & 0 \\ & & P<0.0001 \text { vs. early stage } \\ \text { The degree of mitral regurgitation (\%) } & & & \\ \text { O } & & & \\ \text { I } & 28.2 & 31.9 & 26.8 \\ \text { II } & 50.4 & 47.8 & 51.4 \\ \text { III } & 17.3 & 15.9 & 17.8 \\ \text { IV } & 3.6 & 3.8 & 3.5 \\ & 0.2 & 0.6 & 0 \\ & & P=0.5567 & \text { vs. early stage }\end{array}$

${ }^{*} P<0.05$ vs. early stage.

enzyme (ACE) inhibitors, $\beta$-blockers and calcium channel blockers was lower, and angiotensin receptor blocker (ARB) use was higher in subjects with late- vs. early-stage CAVD.

Data from the previous echocardiographic studies are shown in Table 2. Average left atrial dimension and LV mass index were higher 
Table 3 Laboratory data at the preceding echocardiography

\begin{tabular}{|c|c|c|c|}
\hline & All & Early stage & Late stage \\
\hline Hemoglobin (g per $100 \mathrm{ml}$ ) & $12.5 \pm 2.1$ & $13.3 \pm 1.8$ & $12.2 \pm 2.2^{*}$ \\
\hline White blood cell count $\left(\mu \mathrm{I}^{-1}\right)$ & $5885 \pm 1943$ & $5880 \pm 1486$ & $5887 \pm 2102$ \\
\hline Platelet $\left(10^{4}\right.$ per $\left.\mu \mathrm{l}\right)$ & $19.8 \pm 7.6$ & $20.8 \pm 5.5$ & $19.4 \pm 8.3^{*}$ \\
\hline Serum glucose (mg per $100 \mathrm{ml})$ & $114 \pm 32$ & $107 \pm 26$ & $117 \pm 33^{*}$ \\
\hline Total cholesterol & $193 \pm 38$ & 197 & $192 \pm 39$ \\
\hline Triglyceride (mg per $100 \mathrm{ml}$ ) & $123 \pm 61$ & $117 \pm 49$ & $126 \pm 66$ \\
\hline Creatinine (mg per $100 \mathrm{ml}$ ) & $1.7 \pm 2.4$ & $1.3 \pm 2.0$ & $1.8 \pm 2.6$ \\
\hline eGFR $\left(\mathrm{ml} \mathrm{min}^{-1}\right.$ per $\left.1.73 \mathrm{~m}^{2}\right)$ & $56.9 \pm 27.3$ & $60.8 \pm 22.4$ & $55.3 \pm 28.8^{*}$ \\
\hline
\end{tabular}

Abbreviation: eGFR, glomerular filtration rate.

${ }^{*} P<0.05$ vs. early stage.

in subjects with late- $v$ s. early-stage disease. Aortic regurgitation was observed in more than half of subjects with late-stage CAVD, but in less than half of subjects with early-stage disease.

Laboratory data measured at the time of the preceding echocardiographic examination are shown in Table 3. Hemoglobin and platelet levels and eGFR were lower, whereas serum glucose level was higher in subjects with late- $v s$. early-stage CAVD.

\section{Prognostic factors for progression of CAVD at the early and late stages}

Of the 157 subjects with early-stage CAVD on the preceding echocardiographic study, progression during the follow-up period was observed in 75 subjects and was associated with the use of warfarin and nonuse of ARBs. About half of the subjects without progression were free of mitral regurgitation, but more than $80 \%$ of those with progression did have mitral regurgitation. There was no significant difference in the prevalence of atrial fibrillation between subjects with and without progression (17.8 and $22.0 \%$, respectively). There was no association between progression and any other factors listed in Tables 1-3 (Tables 4 and 5).

Of 399 subjects with late-stage CAVD on the preceding echocardiographic study, progression during the follow-up period was observed in 73 subjects. Those with disease progression were more likely to be female, with smaller LV end-diastolic and end-systolic dimensions and lower hemoglobin levels than those without progression (Tables 4 and 6). There was no significant difference in the prescription rates of any medications listed in Table 4.

Hypertension, diabetes mellitus, dyslipidemia and renal insufficiency were not associated with progression in subjects in either early or late stages of CAVD.

\section{DISCUSSION}

Previous studies have shown that factors such as aging, male gender, high low-density lipoprotein (LDL) levels and a history of hypertension were related to the progression of CAVD. ${ }^{4,6,20}$ However, prognostic factors are likely to differ between the early and late stages, and moreover, the Cardiovascular Health Study has shown the effects of ethnicity on CAVD pathogenesis. ${ }^{6}$ This retrospective study analyzed data from Japanese patients and showed that early-stage subjects with mitral regurgitation, nonuse of ARBs or warfarin use tended to undergo progression of CAVD. In late-stage subjects, progression was associated with female gender, small LV cavity and low level of hemoglobin. Although the prevalence of hypertension, diabetes mellitus, dyslipidemia and renal insufficiency was higher in subjects with late- vs. early-stage disease, none of these comorbidities affected CAVD progression in early- or late-stage disease.
Table 4 Association of each factor with the progression of CAVD

\begin{tabular}{|c|c|c|}
\hline & $\begin{array}{c}\text { Early stage } \\
\text { P-value }\end{array}$ & $\begin{array}{c}\text { Late stage } \\
\text { P-value }\end{array}$ \\
\hline Age & 0.8944 & 0.6187 \\
\hline Gender & 0.1427 & $0.0311^{*}$ \\
\hline Body mass index & 0.5917 & 0.4317 \\
\hline Systolic blood pressure & 0.7145 & 0.5081 \\
\hline Diastolic blood pressure & 0.8594 & 0.4913 \\
\hline \multicolumn{3}{|l|}{ Comorbidity } \\
\hline Hypertension & 0.3331 & 0.4744 \\
\hline Diabetes mellitus & 0.2416 & 0.5502 \\
\hline Dyslipidemia & 0.5380 & 0.8114 \\
\hline Renal insufficiency & 0.6284 & 0.9579 \\
\hline \multicolumn{3}{|l|}{ Medications } \\
\hline Angiotensin-converting enzyme inhibitor & 0.5699 & 0.4971 \\
\hline Angiotensin receptor blocker & $0.0326 *$ & 0.4604 \\
\hline$\beta$-Blocker & 0.4810 & 0.0521 \\
\hline Calcium channel blocker & 0.6974 & 0.6043 \\
\hline Warfarin & $0.0308 *$ & 0.3148 \\
\hline Statins & 0.8156 & 0.4776 \\
\hline Oral hypoglycemic medications & 0.6502 & 0.9641 \\
\hline Insulin & 0.0692 & 0.8388 \\
\hline Left atrial dimension & 0.1437 & 0.7268 \\
\hline Left ventricular end-diastolic dimension & 0.6562 & $0.0144^{*}$ \\
\hline Left ventricular end-systolic dimension & 0.4471 & $0.0120 *$ \\
\hline Ejection fraction & 0.3298 & 0.3087 \\
\hline Left ventricular mass index & 0.1241 & 0.9572 \\
\hline The degree of aortic regurgitation & 0.4532 & 0.1558 \\
\hline The degree of mitral regurgitation & $0.0001^{*}$ & 0.8057 \\
\hline Hemoglobin & 0.3684 & $0.0166^{*}$ \\
\hline White blood cell count & 0.7898 & 0.6567 \\
\hline Platelet & 0.3102 & 0.8894 \\
\hline Serum glucose & 0.6124 & 0.9110 \\
\hline Total cholesterol & 0.6096 & 0.3299 \\
\hline Triglyceride & 0.1737 & 0.0630 \\
\hline Creatinine & 0.6067 & 0.2260 \\
\hline eGFR & 0.8014 & 0.3299 \\
\hline
\end{tabular}

Abbreviations: CAVD, calcific aortic valve disease; eGFR, glomerular filtration rate.

Prognostic factors for progression of early-stage CAVD

We have shown that the prognostic factors for progression of CAVD in Japanese subjects differ between the early and late stages, a conclusion that is compatible with previous studies of Caucasian subjects. ${ }^{4,6,11,17}$

In this study, nonuse of ARBs was associated with progression in early-stage subjects. Previous studies showed that ACE and angiotensin II type 1 receptor were upregulated when angiotensin II was expressed in the calcified human aortic valve compared with the normal valve. ${ }^{21,22}$ An experimental study showed that in hypercholesterolemic rabbits, ARBs prevented lesion formation in the aortic valve, specifically preventing the accumulation of macrophages, myofibroblasts and osteoblasts, upregulation of osteopontin and ACE, and disruption of endothelial integrity. ${ }^{23}$ Findings from these earlier studies and this study suggest that ARBs prevent progression of CAVD during the early stage. However, use of ACE inhibitors did not affect CAVD progression in this study. This may be partly explained by upregulation of chymase and ACE in the calcified aortic valve ${ }^{22}$ and by 
Table 5 Prognostic factors for the progression of CAVD in subjects at the early stage

\begin{tabular}{|c|c|c|}
\hline & \multicolumn{2}{|c|}{ Progression } \\
\hline & + & - \\
\hline \multicolumn{3}{|c|}{ 1. Angiotensin receptor blocker } \\
\hline Use & $16.0 \%$ & $30.5 \%$ \\
\hline No use & $84.0 \%$ & $69.5 \%$ \\
\hline \multicolumn{3}{|c|}{ Odds ratio $0.434(95 \% \mathrm{Cl} ; 0.200,0.944), P=0.0326$} \\
\hline \multicolumn{3}{|c|}{ 2. Warfarin } \\
\hline Use & $24.0 \%$ & $11.0 \%$ \\
\hline No use & $76.0 \%$ & $89.0 \%$ \\
\hline \multicolumn{3}{|c|}{ Odds ratio $2.561(95 \% \mathrm{Cl} ; 1.071,6.126), P=0.0308$} \\
\hline \multicolumn{3}{|c|}{ 3. Mitral regurgitation } \\
\hline 0 & $13.3 \%$ & $48.8 \%$ \\
\hline I & $61.3 \%$ & $35.4 \%$ \\
\hline II & $17.3 \%$ & $14.6 \%$ \\
\hline III & $8.0 \%$ & $0.0 \%$ \\
\hline \multirow[t]{2}{*}{ IV } & $0.0 \%$ & $1.2 \%$ \\
\hline & $P=0.0001$ & \\
\hline
\end{tabular}

Abbreviations: CAVD, calcific aortic valve disease; $\mathrm{Cl}$, confidence interval.

Table 6 Prognostic factors for the progression of CAVD in subjects at the late stage

Progression
$+\quad-$

\begin{tabular}{|c|c|c|}
\hline \multicolumn{3}{|l|}{ 1. Gender } \\
\hline Male & $39.7 \%$ & $53.7 \%$ \\
\hline Female & $60.3 \%$ & $46.3 \%$ \\
\hline
\end{tabular}

Odds ratio $0.569(95 \% \mathrm{Cl} ; 0.339,0.954), P=0.0311$

2. Left ventricular end-diastolic dimension ( $\mathrm{mm}$ )

$$
46 \pm 6
$$

$48 \pm 7$

$P=0.0144$

3. Left ventricular end-systolic dimension ( $\mathrm{mm}$ )

$$
28 \pm 5
$$

$31 \pm 9$

$P=0.0120$

4. Hemoglobin (g per $100 \mathrm{ml}$ )

$11.6 \pm 2.1$

$12.3 \pm 2.2$

$P=0.0166$

Abbreviations: CAVD, calcific aortic valve disease; $\mathrm{Cl}$, confidence interval.

the inadequate suppression of angiotensin II production in the aortic valve by ACE inhibitors.

Warfarin use was also associated with CAVD progression. Matrix $\gamma$-carboxyglutamic acid protein is a mineral-binding extracellular matrix protein and a potent inhibitor of tissue calcification. Vitamin $\mathrm{K}$ antagonists such as warfarin induce the incomplete $\gamma$-carboxylation of matrix $\gamma$-carboxyglutamic acid protein and attenuate the synthesis and function of matrix $\gamma$-carboxyglutamic acid protein. ${ }^{24}$ Previous observational studies in Western countries showed that aortic valve calcifications were significantly larger in patients treated with oral anticoagulants, ${ }^{25,26}$ a finding that is compatible with our current data from Japanese patients. In a society with many elderly, such as in Western countries and Japan, the use of oral anticoagulants to prevent thromboembolic events has increased correspondingly with the rising prevalence of atrial fibrillation, but the effects of warfarin on the progression of CAVD were independent of the presence of atrial fibrillation in this study. We should be aware of this potential adverse effect of warfarin.

Subjects with progression of CAVD had a higher prevalence of mitral regurgitation. Jassal et al. ${ }^{27}$ reported the close relationship between mitral annular calcification and aortic valve calcification in patients with aortic stenosis. We did not assess the effects of mitral annular calcification, but the relationship between mitral regurgitation and progression of early-stage CAVD may be partly explained by the previous finding.

\section{Prognostic factors for progression of late-stage CAVD}

This study showed that more subjects with progression of late-stage CAVD were female. A valvular origin of heart failure, such as aortic stenosis, was more common in women than in men. ${ }^{28,29}$ However, some studies of Caucasian patients found that male gender was a prognostic factor for the development of aortic stenosis, ${ }^{6,7}$ whereas others found no influence of gender. ${ }^{11,20}$ The effects of gender on coronary artery calcification differed even between patient cohorts from the Western countries. ${ }^{30}$ It is plausible that gender influence on the incidence and progression of CAVD differs among racial groups.

The subjects with CAVD progression had a smaller LV cavity than those without progression. There was no difference in LV mass index, and our results therefore indicate that the LV cavity was more concentric in subjects with progression. Aortic valve area is altered by transvalvular flow and increases during exercise. However, exerciseinduced increases are small in subjects with stiff aortic valves leading to excessive pressure overload and concentric remodeling of the LV cavity. Thus, the aortic valve of subjects with concentric LV cavity might have already been more severely injured at the time of the preceding echocardiographic study. Subjects with CAVD progression also had lower hemoglobin levels than those without progression. The enhanced shear stress associated with stenosis of the native aortic valve can theoretically induce intravascular hemolysis. ${ }^{31-33}$ Aortic stenosis is sometimes associated with loss of high molecular von Willebrand multimers and with a greater tendency to bleed. ${ }^{34,35}$ Although these issues are of clinical significance only in cases of severe anemia requiring transfusion, mild anemia in our subjects may exist in part because of these mechanisms. If so, the low hemoglobin level may also indicate that aortic valve injury was more severe at the earlier echocardiographic examination in subjects with progression. Although renal insufficiency is closely related to anemia in patients with cardiovascular diseases, there was no significant difference in serum creatinine or eGFR levels between subjects with $v s$. without progression. These results suggest that CAVD progression is closely related to its severity at baseline in the late-stage subjects, a conclusion that is compatible with findings from previous studies. ${ }^{4,11,20}$ However, the mechanisms of this relationship cannot be explained by this study, and future studies are required.

Differences in comorbidities between subjects with early-and late-stage $C A V D$. The prevalence of hypertension, diabetes mellitus, dyslipidemia and renal insufficiency was higher in subjects with late- $v s$. earlystage CAVD (Table 1). This suggests that the presence of these comorbidities is related to the progression of CAVD; however, none 
were found to be prognostic factors for progression in subjects in either early- or late-stage disease. This discrepancy was also observed in the Cardiovascular Health Study. ${ }^{3,6}$ The follow-up duration was only 2.8 years in this study, and each comorbidity may require a much longer time to affect the aortic valve. Treatment for each comorbidity during the study follow-up period might have masked its effects. In addition, although the data concerning cholesterol fractions were available for less than $70 \%$ of our study subjects, high-density lipoprotein levels tended to be high in subjects without CAVD progression compared with those with progression in both the early- and late-stage groups. This study does not necessarily rule out the effects of comorbidities, particularly those that are untreated, on incidence and/or progression of CAVD.

\section{Study limitations}

There are several limitations of this study. First, this is a retrospective and hospital-based study, and thus, the selection of study subjects might be biased. The results presented here should be confirmed by prospective studies such as JASS Prospective Analysis (https://center. umin.ac.jp/cgi-open-bin/ctr/ctr.cgi?function $=$ brows\&action $=$ brows $\&$ recptno $=$ R000000842\&type $=$ summary\&language $=E)$. Second, it is well known that the prevalence of CAVD is high in patients with chronic kidney disease, particularly those requiring hemodialysis, ${ }^{36}$ but renal insufficiency and eGFR were not identified as predictive factors for progression in this study. This may be because very few hemodialysis patients participated in this study, and the follow-up period was not long enough for the renal insufficiency to exacerbate CAVD. Third, the severity of CAVD at baseline was varied even within each group, and analysis of data from the late-stage subjects suggests that whether or not CAVD progresses is closely related to its severity at baseline. If subjects were divided into more groups, the effects of the baseline severity might have been omitted, and other prognostic factors might have been unmasked. However, the number of patients with severe CAVD (peak aortic transvalvular flow velocity $>4 \mathrm{~m} \mathrm{~s}^{-1}$ ) was too small in this study to identify prognostic factors. To exclude the effects of baseline disease severity and to unmask other prognostic factors, future studies with larger number of subjects are required. Fourth, the follow-up period was not the same between subjects with and without progression in either groups. In the late-stage group, the follow-up period in subjects with progression was shorter than in those without progression. CAVD gradually progresses in general, and thus, even if the follow-up period were lengthened for subjects with progression, the classification of each subject might not be affected. In the early-stage group, the difference in the follow-up period was only 0.39 year, and thus, the effects of a difference in follow-up period were probably small even if present. Fifth, phlebotomy was not necessarily performed in the fasting state, and data concerning cholesterol fractions were unavailable in more than $30 \%$ of our study subjects. Thus, this study might not be able to make conclusive statements about the relationship between CAVD progression and dyslipidemia.

\section{Clinical implications}

Moura et al. ${ }^{37}$ reported the attenuated progression of aortic stenosis in patients who received rosuvastatin because their low-density lipoprotein levels were $>130 \mathrm{mg}$ per $100 \mathrm{ml}$ at baseline, compared with those who did not receive rosuvastatin because their baseline low-density lipoprotein was $<130 \mathrm{mg}$ per $100 \mathrm{ml}$; in addition, the greater decrease in low-density lipoprotein was associated with less progression of aortic stenosis in the rosuvastatin-treated patients. Recent clinical trials failed to find beneficial effects of pharmacological lipid-lowering therapy in preventing progression of aortic stenosis in patients for whom lipid-lowering therapy is not indicated according to current guidelines. ${ }^{19,38,39}$ In this study, the subset of patients with aortic stenosis fell into the cohort of subjects with late-stage CAVD, and as in the previous studies, results from this group found that use of statins or other medications had no effect on the progression of disease in the late stage. Use of statins may attenuate the progression of late-stage CAVD in patients for whom lipid-lowering therapy is indicated according to the current guidelines; however, administering statins beyond these guidelines in an effort to prevent progression of late-stage CAVD through their non-lipid-lowering effects is likely to be unjustified. Currently, there is no pharmacological therapy that is specific for late-stage CAVD.

In contrast, use of ARBs during early-stage CAVD was associated with lack of progression in this study. The prevalence of aortic stenosis is because of high CAVD in developed countries, and the only established therapeutic strategy is aortic valve replacement. This finding suggests that initiation of ARBs during early-stage disease may prevent progression of CAVD and avoid aortic valve replacement. To clarify the effects of ARBs, randomized trials should be performed.

\section{CONCLUSIONS}

Prognostic factors for progression of CAVD differed between earlyand late-stage disease in a Japanese patient cohort. This study suggests that initiation of ARB treatment during the early stage is effective in preventing disease progression, and that caution is indicated in patients treated with oral anticoagulants. Female gender is predictive for disease progression during the late stage, and progression may be more rapid in patients who have a more severe aortic valve injury.

\section{ACKNOWLEDGEMENTS}

This study was supported by grants from the Ministry of Health, Labour and Welfare (Tokyo, Japan). The authors are grateful to Ms Yuko Nakaie for the secretarial assistance.

Participating institutions and investigators: Hiroshima University; Yamamoto $\mathrm{H}$, Utsunomiya H, Hyogo College of Medicine; Masuyama T, Tsujino T, Kagoshima University; Kisanuki A, Toyonaga K, Kawasaki Medical School; Yoshida K, Imai K, Kume T; Kinki University; Hirano Y; Nagoya City University; Ohte N, Wakami K, Osaka University; Yamamoto K, Ohtani T, Nakatani S, Sozu T. University of Occupational and Environmental Health; Otsuji Y, Takeuchi M, Wakayama Medical University; Akasaka T, Tanimoto T.

1 Nkomo VT, Gardin JM, Skelton TN, Gottdiener JS, Scott CG, Enriquez-Sarano M. Burden of valvular heart diseases: a population-based study. Lancet 2006; 368: 1005-1011.

2 lung B, Baron G, Butchart EG, Delahaye F, Gohlke-Bärwolf C, Levang OW, Tornos P, Vanoverschelde JL, Vermeer $F$, Boersma E, Ravaud $P$, Vahanian A. A prospective survey of patients with valvular heart disease in Europe: The Euro Heart Survey on Valvular Heart Disease. Eur Heart J 2003; 24: 1231-1243.

3 Stewart B, Siscovick D, Lind BK, Gardin JM, Gottdiener JS, Smith VE, Kitzman DW, Otto CM. Clinical factors associated with calcific aortic valve disease. Cardiovascular Health Study. J Am Coll Cardiol 1997; 29: 630-634.

4 Bahler RC, Desser DR, Finkelhor RS, Brener SJ, Youssefi M. Factors leading to progression of valvular aortic stenosis. Am J Cardiol 1999; 84: 1044-1048.

5 Otto CM, Lind BK, Kitzman DW, Gersh BJ, Siscovick DS. Association of aortic-valve sclerosis with cardiovascular mortality and morbidity in the elderly. N Engl J Med 1999; 341: 142-147

6 Novaro GM, Katz R, Aviles RJ, Gottdiener JS, Cushman M, Psaty BM, Otto CM, Griffin BP. Clinical factors, but not C-reactive protein, predict progression of calcific aortic-valve disease: The Cardiovascular Health Study. J Am Coll Cardiol 2007; 50: 1992-1999.

7 Ortlepp JR, Schmitz F, Mevissen V, Weiß S, Huster J, Dronskowski R, Langebartels G, Autschbach R, Zerres K, Weber C, Hanrath P, Hoffmann R. The amount of calciumdeficient hexagonal hydroxyapatite in aortic valves is influenced by gender and associated with genetic polymorphisms in patients with severe calcific aortic stenosis. Eur Heart J 2004; 25: 514-522. 
8 O'Brien KD. Pathogenesis of calcific aortic valve disease; a disease process comes of age (and a good deal more). Arterioscler Thromb Vasc Biol 2006; 26: 1721-1728.

9 Goldbarg SH, Elmariah S, Miller MA, Fuster V. Insights into degenerative aortic valve disease. J Am Coll Cardiol 2007; 50: 1205-1213.

10 Miller JD, Chu Y, Brooks RM, Richenbacher WE, Peña-Silva R, Heistad DD. Dysregulation of antioxidant mechanisms contributes to increased oxidative stress in calcific aortic valvular stenosis in humans. J Am Coll Cardiol 2008; 52: 843-850.

11 Otto CM, Burwash IG, Legget ME, Munt BI, Fujioka M, Healy NL, Kraft CD, Miyake-Hull CY, Schwaegler RG. Prospective study of asymptomatic valvular aortic stenosis: clinical, echocardiographic, and exercise predictors of outcome. Circulation 1997; 95: 2262-2270.

12 Matsuo S, Imai E, Horio M, Yasuda Y, Tomita K, Nitta K, Yamagata K, Tomino Y, Yokoyama $\mathrm{H}$, Hishida $\mathrm{A}$. Revised equations for estimated GFR from serum creatinine in Japan. Am J Kidney Dis 2009; 53: 982-992.

13 Yamaguchi H, Yoshida J, Yamamoto K, Sakata Y, Mano T, Akehi N, Hori M, Lim YJ, Mishima M, Masuyama T. Elevation of plasma brain natriuretic peptide is a hallmark of diastolic heart failure independent of ventricular hypertrophy. J Am Coll Cardiol 2004; 43: 55-60.

14 Nishio M, Sakata Y, Mano T, Ohtani T, Takeda Y, Hori M, Yamamoto K. Difference of clinical characteristics between hypertensive patients with and without diastolic heart failure: role of diastolic dysfunction and renal insufficiency. Hypertens Res 2008; 31 . 1865-1872.

15 Quinones MA, Waggoner AD, Reduto LA, Nelson JG, Young JB, Winters Jr WL, Ribeiro LG, Miller RR. A new simplified and accurate method for determining ejection fraction with two-dimensional echocardiography. Circulation 1981; 64: 744-753.

16 Lang RM, Bierig M, Devereux RB, Flachskampf FA, Foster E, Pellikka PA, Picard MH, Roman MJ, Seward J, Shanewise JS, Solomon SD, Spencer KT, St John Sutton M, Stewart WJ. Recommendations for chamber quantification: a report from the American Society of Echocardiography's guidelines and quantification writing group, developed in conjunction with the European Association of Echocardiography, a branch of the European Society of Cardiology. J Am Soc Echocardiogr 2005; 18 : 1440-1463.

17 Faggiano P, Antonini-Canterin F, Erlicher A, Romeo C, Cervesato E, Pavan D, Piazza R, Huang G, Nicolosi GL. Progression of aortic valve sclerosis to aortic stenosis. Am J Cardiol 2003; 91: 99-101.

18 Cosmi JE, Kort S, Tunick PA, Rosenzweig BP, Freedberg RS, Katz ES, Applebaum RM, Kronzon I. The risk of the development of aortic stenosis in patients with benign aortic valve thickening. Arch Intern Med 2002; 162: 2345-2347.

19 Dichtl W, Alber HF, Feuchtner GM, Hintringer F, Reinthaler M, Bartel T, Süssenbacher A, Grander W, Ulmer H, Pachinger O, Müller S. Prognosis and risk factors in patients with asymptomatic aortic stenosis and their modulation by atorvastatin $(20 \mathrm{mg}) . \mathrm{Am} \mathrm{J}$ Cardiol 2008; 102: 743-748.

20 Rosenhek R, Binder T, Porenta G, Lang I, Christ G, Schemper M, Maurer G, Baumgartner $\mathrm{H}$. Predictors of outcome in severe, asymptomatic aortic stenosis. $N$ Engl J Med 2000; 343: 611-617.

21 O'Brien KD, Shavelle DM, Caulfield MT, McDonald TO, Olin-Lewis K, Otto CM, Probstfield JL. Association of angiotensin-converting enzyme with low-density lipoprotein in aortic valvular lesions and in human plasma. Circulation 2002; 106 : 2224-2230.

22 Helske S, Lindstedt KA, Laine M, Mäyränpää M, Werkkala K, Lommi J, Turto H, Kupari $\mathrm{M}$, Kovanen PT. Induction of local angiotensin II-producing systems in stenotic aortic valves. J Am Coll Cardiol 2004; 44: 1859-1866.

23 Arishiro K, Hoshiga M, Negoro N, Jin D, Takai S, Miyazaki M, Ishihara T, Hanafusa T. Angiotensin receptor- 1 blocker inhibits atherosclerotic changes and endothelial dis- ruption of the aortic valve in hypercholesterolemic rabbits. J Am Coll Cardiol 2007; 49: 1482-1489.

24 Vermeer C. Gamma-carboxyglutamate-containing proteins and the vitamin K-dependent carboxylase. Biochem J 1990; 266: 625-636.

25 Koos R, Mahnken AH, Muhlenbruch G, Brandenburg V, Pflueger B, Wildberger JE, Kuhl HP. Relation of oral anticoagulation to cardiac valvular and coronary calcium assessed by multislice spiral computed tomography. Am J Cardiol 2005; 96: 747-749.

26 Schurgers LJ, Aebert H, Vermeer C, Bultmann B, Janzen J. Oral anticoagulant treatment: friend or foe in cardiovascular disease? Blood 2004; 104: 3231-3232.

27 Jassal DS, Tam JW, Bhagirath KM, Gaboury I, Sochowski RA, Dumesnil JG, Giannoccaro PJ, Jue J, Pandey AS, Joyner CD, Teo KK, Chan KL. Association of mitral annular calcification and aortic valve morphology: a substudy of the aortic stenosis progression observation measuring effects of rosuvastatin (ASTRONOMER) study. Eur Heart J 2008; 29: 1542-1547.

28 O'Meara E, Clayton T, McEntegart MB, McMurray JJV, Piña IL, Granger CB, stergren J, Michelson EL, Solomon SD, Pocock S, Yusuf S, Swedberg K, Pfeffer MA. Sex differences in clinical characteristics and prognosis in a broad spectrum of patients with heart failure: results of the Candesartan in Heart failure: Assessment of Reduction in Mortality and morbidity (CHARM) program. Circulation 2007; 115: 3111-3120.

29 Nieminen MS, Harjola VP, Hochadel M, Drexler H, Komajda M, Brutsaert D, Dickstein K, Ponikowski P, Tavazzi L, Follath F, Lopez-Sendon JL. Gender related differences in patients presenting with acute heart failure. Results from EuroHeart Failure Survey II. Eur J Heart Fail 2008; 10: 140-148.

30 Erbel R, Delaney JA, Lehmann N, McClelland RL, Möhlenkamp S, Kronmal RA, Schmermund A, Moebus S, Dragano N, Stang A, Jöckel KH, Budoff MJ. Signs of subclinical coronary atherosclerosis in relation to risk factor distribution in the MultiEthnic Study of Atherosclerosis (MESA) and the Heinz Nixdorf Recall Study (HNR). Eur Heart J 2008; 29: 2782-2791.

31 Nevaril CG, Lynch EC, Alfrey Jr CP, Hellums JD. Erythrocyte damage and destruction induced by shearing stress. J Lab Clin Med 1968; 71: 784-790.

32 MacCallum RN, Lynch EC, Hellums JD, Alfrey CP Jr. Fragility of abnormal erythrocytes evaluated by response to shear stress. J Lab Clin Med 1975; 85: 67-74.

33 Jacobson RJ, Rath CE, Perloff JK. Intravascular haemolysis and thrombocytopenia in left ventricular outflow obstruction. Br Heart J 1973; 35: 849-854.

34 Pareti FI, Lattuada A, Bressi C. Proteolysis of von Willebrand factor and shear stressinduced platelet aggregation in patients with aortic valve stenosis. Circulation 2000; 102: 1290-1295.

35 Vincentelli A, Susen S, Le Tourneau T, Six I, Fabre O, Juthier F, Bauters A, Decoene C, Goudemand J, Prat A, Jude B. Acquired von Willebrand syndrome in aortic stenosis. N Engl J Med 2003; 349: 343-349.

36 Umana E, Ahmed W, Alpert MA. Valvular and perivalvular abnormalities in end-stage renal disease. Am J Med Sci 2003; 325: 237-242.

37 Moura LM, Ramos SF, Zamorano JL, Barros IM, Azevedo LF, Rocha-Gonçalves F, Rajamannan NM. Rosuvastatin affecting aortic valve endothelium to slow the progression of aortic stenosis. J Am Coll Cardiol 2007; 49: 554-561.

38 Cowell SJ, Newby DE, Prescott RJ, Bloomfield P, Reid J, Northridge DB, Boon NA. A randomized trial of intensive lipid-lowering therapy in calcific aortic stenosis. $N$ Eng/ J Med 2005; 352: 2389-2397.

39 Rossebø AB, Pedersen TR, Boman K, Brudi P, Chambers JB, Egstrup K, Gerdts E, Gohlke-Bärwolf C, Holme I, Kesäniemi YA, Malbecq W, Nienaber CA, Ray S, Skjærpe T, Wachtell K, Willenheimer R. Intensive lipid lowering with simvastatin and ezetimibe in aortic stenosis. N Engl J Med 2008; 359: 1343-1356. 